\title{
IMPROVEMENT OF MOBILE MILKING PARLOURS IN SMALL DAIRY FARMS INCLUDING TECHNICAL AND FUNCTIONAL ASPECTS
}

\author{
Marek Gaworski ${ }^{1}$, Pavel Kic ${ }^{2}$ \\ ${ }^{1}$ Warsaw University of Life Sciences, Warsaw, Poland; \\ ${ }^{2}$ Czech University of Life Sciences, Prague, Czech Republic \\ marek_gaworski@sggw.pl,kic@tf.czu.cz
}

\begin{abstract}
The aim of this paper was to show and analyse selected technical parameters of mobile milking parlours, which could help in solving the problem of milking on some dairy farms. The article was based on the experience of operating a specific dairy farm in Poland, intended for 28 cows and using a mobile milking technique. The measured consumption of fuel by the tractor used to operate the mobile milking parlour in the investigated dairy farm was (mean \pm SD) $2.6 \pm 0.4 \mathrm{~kg} \cdot \mathrm{h}^{-1}$ for morning and evening milking. Given the measured milking time, cow herd size and milk yield, it was possible to calculate the fuel consumption, which amounted to $0.11 \pm 0.003 \mathrm{~kg} \cdot \mathrm{cow}^{-1} \cdot \mathrm{milking}^{-1}$ and $8.44 \pm 1.3 \mathrm{~kg} \cdot \mathrm{t}^{-1}$ ( $\mathrm{kg}$ of diesel fuel per ton of milk). The cost of diesel fuel was about $1.16 \mathrm{EUR} \cdot \mathrm{kg}^{-1}$, so the cost of the fuel consumed by the tractor was about $0.13 \pm 0.004 \mathrm{EUR} \cdot \mathrm{cow}^{-1} \cdot \mathrm{milking}^{-1}$. In order to extend the research analyses, model calculations were used, based on the methodology applied in evaluation as well as optimization of parlours, created in the Czech Republic. The results of measurements and calculations in the subject farm were compared against possible future technological improvements and a farm with enlarged capacity of 50 cows. The process of evaluation of the milking parlour parameters was based on the available information and results of previous research conducted in Polish dairy farms in recent years. The time spent on milking and the final specific direct costs are the main parameters, which enable the evaluation and selection of a suitable milking parlour for a dairy farm.
\end{abstract}

Keywords: costs, cows, equipment, milking process, mobile milking parlour, pasture.

\section{Introduction}

Currently, some farmers allow their cows of dairy herd longest stay on pasture (from spring to autumn). This is based on requirements related to long-term stay of dairy cows in fresh air, natural intake of feed on pasture, reducing problems with removal of manure, and at the same time, natural fertilization of land. Many aspects related to pasture, cows and technological solutions constitute a significant field of research considering the efficiency and profitability of dairy systems where pasture grazing plays a key role $[1 ; 2]$.

On the other hand, however, a cow herd kept out of the barn has greater demands in terms of organization of pasture, and if there is a greater distance between the pasture and the barn, regular milking may be a problem. In such cases, a solution may be provided by the use of mobile devices and milking parlours.

The leading companies producing milking equipment usually offer a variety of constructions of milking parlours recommended for different capacities of farms, but they do not offer any mobile milking machinery. The principles of selection of a suitable capacity of mobile milking machines are similar to those applicable to traditional milking parlours. Some research considerations discuss technical problems and parameter selection for the design of a mobile goat milking installation [3]. The problem of selection of the milking system and its evaluation given the different production conditions in dairy farm(s) is the source of some models, including the whole-farm model for pasturebased dairy systems [4-7]. However, a complete universal approach that could be adopted everywhere does not exist. Some parameters of milking parlours are possible to calculate based on some formulas using biological, technical and technological factors, which create an effective milking system in the dairy farm [8-9].

The aim of this paper was to present and analyse selected technical parameters of mobile milking parlours, which could help in solving the problem of milking in dairy farms where cows are kept on the pasture only a few months a year.

\section{Materials and methods}

The research considerations were based on the experience of a dairy farm with a cow herd size of 28 animals, using a mobile milking technique. The farm is situated in the north of Poland, near Vistula River, where big areas of pasture enable farmers to keep their cows outdoors. The average distance 
between the dairy farm and the pasture was $2-3 \mathrm{~km}$, a maximum of $5 \mathrm{~km}$, thus the cows were kept on the pastures throughout the period of six months a year (from the beginning of May to the end of October). The dairy farm is the owner of a few independent plots of the grazing land, therefore the cows moved between the pastures during the feeding season.

The farm was visited twice in 2016, i.e. in May and August, to collect some data concerning milking of dairy cows with the use of a mobile milking parlour. The data were collected to verify some model considerations developed in the paper.

The mobile milking parlour used in the farm was built on the basis of a two-wheeled trailer attached to a tractor (Fig. 1). It was a Polish brand of tractor, Ursus C-330, with the engine power of $30 \mathrm{hp}$. The tractor was equipped with an SLA (Sealed Lead-Acid) battery.

The trailer, covered with a roof and enclosed by three full walls, was equipped inside with vacuum installation, some parts of milking installation, electric elements and the tank to collect milk. The vacuum pump is driven by the PTO (power take-off shaft) of the tractor, while the electrical receivers (e.g., the milk intermediate container cooperating with a milking pump PLMP37 and a single-phase induction motor with a power of $0.45 \mathrm{~kW}$ ) are battery powered, including the use of a converter (DC/AC - Hartte) to transform direct current into variable current. On the outside of the walls, two pipes were installed, i.e. the vacuum pipe and milk pipe, connected to the DeLaval milking unit. Four milking units were used to milk the cows in the pasture conditions. The investigated mobile milking parlour was designed and constructed at the beginning of 2016, therefore the observations were made during the first year of operation of the parlour. In the course of observations, the following data were collected: time necessary to move the cows from the pasture to the location of the mobile milking parlour, time spent to prepare cows for milking, milking time and operation of the parlour. Moreover, the data related to the fuel (diesel fuel) consumption by the tractor were also collected for the purpose of more in-depth analyses. The fuel consumption by the tractor was measured using the method of full fuel tank, including morning and evening milking. Accordingly, it was possible to calculate some indices concerning fuel consumption in relation to the size of the cow herd and milk yield. Data regarding the amount of collected milk per single milking on the pasture were also gathered for more exact calculations. The annual milk yield per cow in the investigated dairy farm was $7900 \mathrm{~kg} \cdot \mathrm{cow}^{-1} \cdot \mathrm{year}^{-1}$.

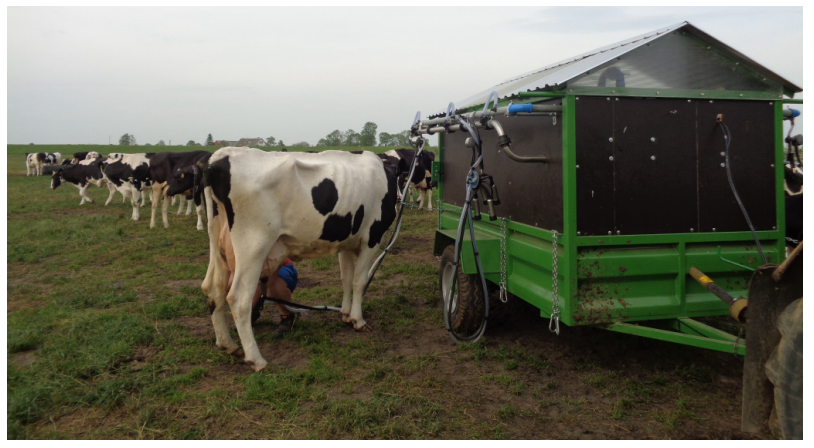

Fig. 1. View of the subject mobile milking parlour

In order to extend the research considerations, model calculations were used, based on the methodology applied in evaluation as well as optimization of parlours, created in the Czech Republic. The methodology includes technical and economic parameters as the basic elements of the mathematical model. The results of measurements and calculations in the subject farm were compared against possible future technological improvements and a farm with enlarged capacity of 50 cows, including two options: milking without automation and automated milking.

The determination of the main parameters used for evaluation and optimization of suitable milking parlours is based on the model principles, formulas and equations described in $[10 ; 11]$. The parameters of the farm include the number of all cows on the farm $N_{c}$, cow; the number of lactating cows on the farm $N$, cow; and the time limit per milking $T_{p}$, min.

First, the main parameters of the dairy farm and milking operations were calculated, which mainly consisted of the required capacity of the milking parlour $Q_{P L}, \operatorname{cow} \cdot \mathrm{min}^{-1}$; the labour requirement for milking per cow $t_{r c}$, $\mathrm{min} \cdot \mathrm{cow}^{-1}$; the working capacity of one milker $W_{d}$, cow. $\min ^{-1}$; the maximum 
number of clusters per milker $n_{s}$, the theoretical number of milking stalls in the parlour m; the actual number of milking stalls in the parlour $m_{d}$, the maximum reasonable number of milkers per parlour $n_{d m}$ (a very important criterion if you wish to avoid the idle time or complicated work for milkers); the theoretical, required number of milkers $n_{d}$, the actual number of milkers for the whole farm $n_{d s}$; the actual capacity of the milking parlour $Q_{L S}, \mathrm{cow} \cdot \mathrm{min}^{-1}$; the labour requirement for milking per cow and day $T_{d}$, min; and the total duration of milking, including preparatory operations and finishing work after milking $T_{c d}$, min.

The economic criteria used for evaluation and comparison of different variants are the final specific direct costs of the milking parlour ${ }^{u} C_{M P}$, EUR $\cdot \operatorname{cow}^{-1} \cdot$ year ${ }^{-1}$, which are the sum of the specific labour costs per cow and year ${ }^{n} C_{W}$, EUR $\cdot \operatorname{cow}^{-1} \cdot$ year $^{-1}$; the specific costs of the milking equipment ${ }^{u} C_{P}$, EUR $\cdot \operatorname{cow}^{-1} \cdot$ year ${ }^{-1}$; and the specific costs of the consumed supplies ${ }^{u} C_{S}$, EUR $\cdot \operatorname{cow}^{-1} \cdot$ year $^{-1}$.

\section{Results and discussion}

The measured fuel consumption by the tractor used to operate the mobile milking parlour in the investigated dairy farm (with 28 cows) was (mean \pm SD) $2.6 \pm 0.4 \mathrm{~kg} \cdot \mathrm{h}^{-1}$ for morning and evening milking. Given the time of milking, the size of the cow herd and milk yield, it was possible to calculate the fuel consumption, which amounted to $0.11 \pm 0.003 \mathrm{~kg} \cdot \mathrm{cow}^{-1} \cdot \mathrm{milking}^{-1}$ and $8.44 \pm 1.3 \mathrm{~kg} \cdot \mathrm{t}^{-1}$ ( $\mathrm{kg}$ of diesel fuel per ton of milk). The cost of diesel fuel was about $1.16 \mathrm{EUR} \cdot \mathrm{kg}^{-1}$, thus the cost of the fuel consumed by the tractor was about $0.13 \pm 0.004 \mathrm{EUR} \cdot \mathrm{cow}^{-1} \cdot \mathrm{milking}^{-1}$.

The results of the calculations of the actual and expected situation on a dairy farm are presented in Tables 1 and 2 and in Fig. 2-5. For A1 and B1 variants, a standard level of technical equipment was applied. Two milkers are employed in both variants of the milking parlour $\left(N_{c}=28\right.$ cows $)$ and $\left(N_{c}=50\right.$ cows), which uses a very simple manual technology. Therefore, the work capacity of one milker $W_{d}=0.22 \mathrm{cow} \cdot \mathrm{min}^{-1}$ is rather low.

Table 1

Main parameters of the dairy farm and milking operations

\begin{tabular}{|c|c|c|c|c|c|}
\hline Parameter & Units & $\begin{array}{c}\text { Subject farm } \\
\text { A1 }\end{array}$ & $\begin{array}{c}\text { Improved } \\
\text { subject farm } \\
\text { A2 }\end{array}$ & $\begin{array}{c}\text { Increased } \\
\text { capacity of subject } \\
\text { farm B1 }\end{array}$ & $\begin{array}{c}\text { Increased } \\
\text { capacity of } \\
\text { improved farm B2 }\end{array}$ \\
\hline $\begin{array}{c}\text { Technical } \\
\text { level }\end{array}$ & - & $\begin{array}{c}\text { Without } \\
\text { automation }\end{array}$ & Automated & Without automation & Automated \\
\hline$N_{c}$ & cows & 28 & 28 & 50 & 50 \\
\hline$N$ & cows & 24 & 24 & 43 & 43 \\
\hline$T_{p}$ & min & 50 & 50 & 60 & 60 \\
\hline$Q_{p l}$ & cow· $\min ^{-1}$ & 0.53 & 0.53 & 0.79 & 0.79 \\
\hline$t_{r c}$ & min·cow ${ }^{-1}$ & 4.59 & 1.66 & 4.59 & 1.66 \\
\hline$W_{d}$ & cow·min & 0.22 & 0.60 & 0.22 & 0.60 \\
\hline$n_{s}$ & $\mathrm{pcs}$ & 1.58 & 3.91 & 1.58 & 3.91 \\
\hline$m$ & $\mathrm{pcs}$ & 3.87 & 3.47 & 5.75 & 5.16 \\
\hline$m_{d}$ & $\mathrm{pcs}$ & 4 & 4 & 4 & 4 \\
\hline$n_{d m}$ & $\mathrm{pcs}$ & 2.53 & 1.02 & 2.53 & 1.02 \\
\hline$n_{d}$ & $\mathrm{pcs}$ & 2.45 & 0.87 & 3.64 & 1.32 \\
\hline$n_{d s}$ & $\mathrm{pcs}$ & 2 & 1 & 2 & 1 \\
\hline$Q_{L S}$ & $\mathrm{cow} \cdot \mathrm{min}^{-1}$ & 0.44 & 0.60 & 0.44 & 0.60 \\
\hline$T_{d}$ & $\mathrm{~min}$ & 11.59 & 5.82 & 10.53 & 4.72 \\
\hline$T_{c d}$ & $\mathrm{~min}$ & 69.54 & 69.86 & 112.79 & 101.19 \\
\hline
\end{tabular}

Explanation of symbols: $N_{c}-$ number of all cows on the farm; $N$ - number of lactating cows on the farm; $T_{p}$ - time limit per one milking; $Q_{P L}$ - required capacity of the milking parlour; $t_{r c}$ - labour requirement for milking per cow; $W_{d}$ - working capacity of one milker; $n_{s}$ - maximum number of clusters per milker; $m$ - theoretical number of milking stalls in the parlour; $m_{d}-$ actual number of milking stalls in the parlour; $n_{d m}$ - maximum reasonable number of milkers per parlour; $n_{d}$ - theoretical required number of milkers; $n_{d s}$ - actual number of milkers for the whole farm; $Q_{L S}-$ actual capacity of the milking parlour; $T_{d}-$ labour requirement for milking per cow and day; $T_{c d}$ - total time of duration of one milking including preparatory operations and finishing work after milking. 
The difference between the variants $\mathrm{A} 1$ and $\mathrm{A} 2$ is rather insignificant. The total duration of milking, including preparatory operations and finishing work after milking, $T_{c d}$ in both these variants, is nearly the same and similar to the time limit per milking $T_{p}$. The final specific direct costs of the milking parlour ${ }^{n} C_{M P}$ are also very similar, but the proportions between the specific labour costs ${ }^{u} C_{W}$, and the specific costs of the milking equipment ${ }^{u} C_{P}$ are reverse.

Table 2

Specific direct costs of the milking parlour and milking operations

\begin{tabular}{|c|c|c|c|c|c|}
\hline Parameter & Units & $\begin{array}{c}\text { Subject farm } \\
\text { A1 }\end{array}$ & $\begin{array}{c}\text { Improved } \\
\text { subject farm } \\
\text { A2 }\end{array}$ & $\begin{array}{c}\text { Increased } \\
\text { capacity of } \\
\text { subject farm } \\
\text { B1 }\end{array}$ & $\begin{array}{c}\text { Increased } \\
\text { capacity of } \\
\text { improved } \\
\text { farm B2 }\end{array}$ \\
\hline $\begin{array}{c}\text { Technical } \\
\text { level }\end{array}$ & - & $\begin{array}{c}\text { Without } \\
\text { automation }\end{array}$ & Automated & $\begin{array}{c}\text { Without } \\
\text { automation }\end{array}$ & Automated \\
\hline${ }^{u} C_{W}$ & EUR $\cdot \mathrm{cow}^{-1} \cdot \mathrm{year}^{-1}$ & 105.765 & 53.126 & 96.062 & 43.088 \\
\hline${ }^{u} C_{P}$ & EUR $\cdot \mathrm{cow}^{-1} \cdot \mathrm{year}^{-1}$ & 71.571 & 119.286 & 40.08 & 66.8 \\
\hline${ }^{u} C_{S}$ & EUR $\cdot \mathrm{cow}^{-1} \cdot \mathrm{year}^{-1}$ & 73.605 & 73.764 & 58.39 & 55.161 \\
\hline${ }^{u} C_{M P}$ & EUR $\cdot \mathrm{cow}^{-1} \cdot \mathrm{year}^{-1}$ & 250.941 & 246.176 & 194.532 & 165.049 \\
\hline
\end{tabular}

Explanation of symbols: ${ }^{\prime} C_{W}$ - the sum of the specific labour costs per cow and year; ${ }^{\prime} C_{P}$ - specific costs of the milking equipment; ${ }^{\prime} C_{S}$ - specific costs of consumed supplies; ${ }^{\prime} C_{M P}$ - final specific direct costs of the milking parlour.

One milker is supposed to work in the variants of the milking parlour: A2 ( $N_{c}=28$ cows) and B2 $\left(N_{c}=50\right.$ cows $)$. More expensive technological equipment of this milking parlour results in the increase of the specific costs of the milking equipment ${ }^{u} C_{P}$, but lower specific costs of labour ${ }^{u} C_{W}$.

The more progressive farm, variant B with 50 cows, brings changes in terms of the final time and costs (Tab. 1 and 2, and Fig. 4 and 5.) It seems suitable to increase the actual number of milking stalls per parlour $m_{d}$ to 6 milking stalls, according to the calculated theoretical number of milking stalls per parlour $\mathrm{m}$. This would also allow for the change of the number of milkers per parlour according to the calculated number, including, as suggested by other investigations [12], the optimal number of clusters per milker. In the subject case, variant B2 is more suitable as it requires shorter milking time and also lower expenses than B1.

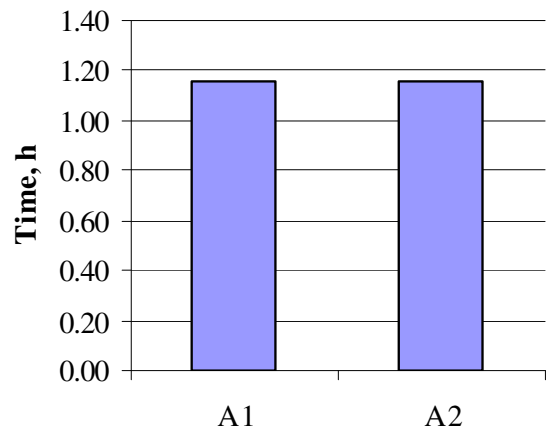

Fig. 2. Milking time, subject farm A with 28 cows by variant of milking parlour

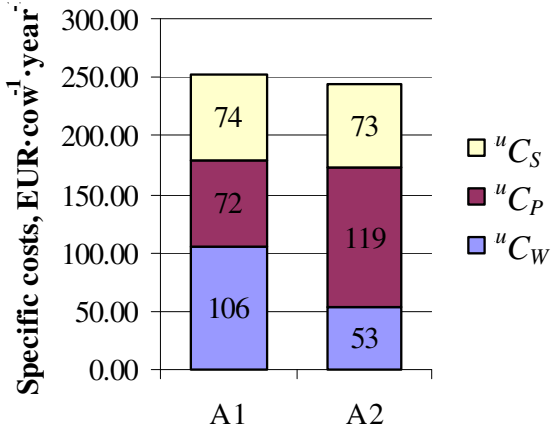

Fig. 3. Specific costs, subject farm A with 28 cows by variant of milking parlour

Detailed research considerations, where some economic parameters associated with different technology levels (medium and high) as well as different herd sizes (70 and 140 cows), were developed by [13] including several different measured components in a pasture-based dairy system evaluation. The different number of the possible data related to milking confirms that the proposal to elaborate a dairy system model [14] can be an important way to identify and find effective solution(s) for most dairy farms interested in increasing their cow herds and the dairy production potential.

The factors, which decide about profitability of dairy production, are often discussed in literature. There is an opinion that a profitable dairy production system is not the one with the greatest milk production, but the one with the lowest total costs [15]. Based on the cost criterion, we may suggest that in the Polish scenario, a suitable system is the low-cost grass-based system of dairy production. 


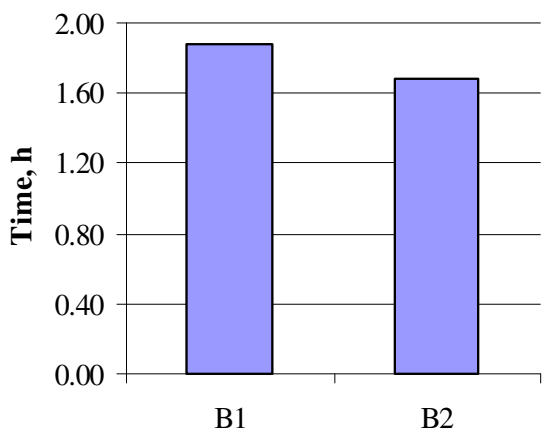

Fig. 4. Milking time, future farm B with $\mathbf{5 0}$ cows by variant of milking parlour

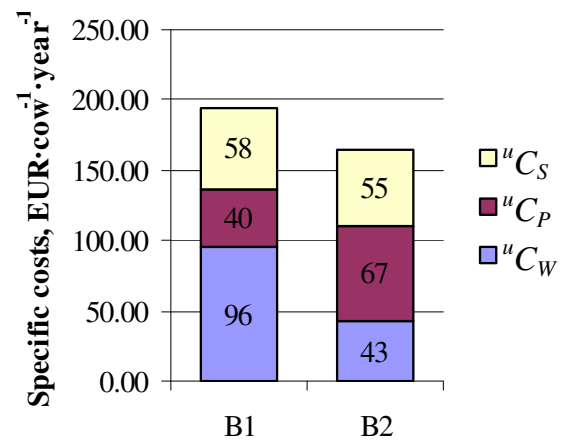

Fig. 5. Specific costs, future farm B with 50 cows by variant of milking parlour

\section{Conclusions}

1. The choice of the optimal type of milking parlour, corresponding to the overall concept of the farm and meeting all operational requirements under acceptable economic conditions, is an area where a new research approach can be developed and verified.

2. Based on the results of the model analyses we may suggest that automation in cow milking provides better results with larger cow herds, especially in terms of the specific costs of the milking equipment expressed in EUR per cow and year.

3. A mobile milking parlour may be a source of increased cow milking efficiency. However, the observations indicate that effective washing of the milking installation must be also ensured, which can generate additional costs related to the use of sophisticated equipment in the farm.

\section{References}

1. Hanson G.D., Cunningham L.C., Morehart M.J., Parsons R.L. Profitability of moderate intensive grazing of dairy cows in the Northeast. Journal of Dairy Science, 81(3), 1998, pp. 821-829.

2. Tozer P.R., Bargo F., Muller L.D. 2004. The effect of pasture allowance and supplementation on feed efficiency and profitability of dairy systems. Journal of Dairy Science, 87(9), 2004, pp. 2902-2911.

3. Rossel D., Laurel H., O., Carrillo A.R.Q. Parameter selection for the design of a mobile goat milking installation. Interciencia, vol. 30, 2005, pp. 565-570. (in Spanish).

4. Priekulis J., Laurs A. Research in automatic milking system capacity. Proceedings 11th International scientific conference Engineering for rural development, May 24-25, Jelgava, Latvia University of Agriculture, 2012, pp. 47-51.

5. Brunsch R., Kaufmann O., Lupfert. T. Rinderhaltung in Laufstallen (Loose housing of cattle). Stuttgart: Eugen Ulmer, 1996. 132 p. (in German).

6. Chiumenti R. Costruzioni rurali (Rural buildings). Milano: Edagricole scolastico, 2004. 479 p. (in Italian).

7. Beukes P.C., Palliser C.C., Macdonald K.A., Lancaster J.A.S., Levy G., Thorrold B.S., Wastney M.E. Whole-farm model for pasture-based dairy systems. Journal of Dairy Science, 91(6), 2008, pp. 2353-2360.

8. Gaworski M., Leola A. Effect of technical and biological potential on dairy production development. Agronomy Research, 12 (1), 2014, pp. 215-222.

9. Gaworski M., Priekulis J. Analysis of milking system development on example of two Baltic countries. Proceedings of 13th International scientific conference Engineering for Rural Development, May 29-30, Jelgava, Latvia University of Agriculture, 2014, pp. 79-84.

10. Kic P. Mathematical model for optimal arrangement of milking parlor. Agricultural Engineering International: CIGR Journal, 2015a, pp. 71-79.

11. Kic P. Criteria for optimization of milking parlour on dairy farm. Proceedings 14th International scientific conference Engineering for Rural Development, May 20-22, Jelgava, Latvia University of Agriculture, 2015b, pp. 106-111. 
12. Hansen M.N. Optimal number of clusters per milker. Journal of Agricultural Engineering Research, 72 (4), 1999, pp. 341-346

13. Shortall J., Shalloo L., Foley C., Sleator R.D., O’Brien B. Investment appraisal of automatic milking and conventional milking technologies in a pasture-based dairy system. Journal of Dairy Science, 99(9), 2016, pp. 7700-7713.

14. Shalloo L., Dillon P., Rath M., Wallace M. Description and validation of the Moorepark Dairy System Model. Journal of Dairy Science, 87(6), 2004, pp. 1945-1959.

15. Ramsbottom G., Horan B., Berry D.P., Roche J.R. Factors associated with the financial performance of spring-calving, pasture-based dairy farms. Journal of Dairy Science, 98(5), 2015, pp. 3526-3540. 